\title{
ON A FUNCTIONAL EQUATION RELATED TO TWO-VARIABLE CAUCHY MEANS
}

\author{
TIBOR KISS AND Zsolt PÁLES
}

Abstract. In this paper, we are dealing with the solution of the functional equation

$$
\varphi\left(\frac{x+y}{2}\right)(f(x)-f(y))=F(x)-F(y),
$$

concerning the unknown functions $\varphi, f$ and $F$ defined on a same open subinterval of the reals. Improving the previous results related to this topic, we describe the solution triplets $(\varphi, f, F)$ assuming only the continuity of $\varphi$.

As an application, under natural conditions, we also solve the equality problem of twovariable Cauchy means and two-variable quasi-arithmetic means.

Mathematics subject classification (2010): 39B52, 46C99.

Keywords and phrases: Cauchy mean, quasi-arithmetic mean, functional equations involving means, equality problem of means.

\section{REFERENCES}

[1] J. ACZÉL, A mean value property of the derivative of quadratic polynomials-without mean values and derivatives, Math. Mag., 58(1):42-45, 1985.

[2] J. ACZÉL AND M. KUCZMA, On two mean value properties and functional equations associated with them, Aequationes Math., 38(2-3):216-235, 1989.

[3] Z. Balogh, O. O. Ibrogimov, And B. S. Mityagin, Functional equations and the Cauchy mean value theorem, Aequationes Math., 90(4):683-697, 2016.

[4] L. R. BERRONE, Invariance of the Cauchy mean-value expression with an application to the problem of representation of Cauchy means, Int. J. Math. Math. Sci., (18):2895-2912, 2005.

[5] L. R. Berrone, Generalized Cauchy means, Aequationes Math., 90(2):307-328, 2016.

[6] L. R. Berrone AND J. Moro, On means generated through the Cauchy mean value theorem, Aequationes Math., 60(1-2):1-14, 2000.

[7] N. G. DE BRUIJN, Functions whose differences belong to a given class, Nieuw Arch. Wisk. (2), 23:194-218, 1951.

[8] N. G. DE BRUIJN, A difference property for Riemann integrable functions and for some similar classes of functions, Nederl. Akad. Wetensch. Proc. Ser. A. 55 = Indagationes Math., 14:145-151, 1952.

[9] J. GeR, On Sahoo-Riedel equations on a real interval, Aequationes Math., 63(1-2):168-179, 2002.

[10] Sh. HARUKI, A property of quadratic polynomials, Amer. Math. Monthly, 86(7):577-579, 1979.

[11] P. L. KANNAPPAN AND P. K. SAHOO, A property of quadratic polynomials in two variables, J. Math. Phys. Sci., 31(2-3):65-74 (2001), 1997.

[12] T. KISS AND Zs. PÁLES, On a functional equation related to two-variable weighted quasi-arithmetic means, J. Difference Equ. Appl., 24(1):107-126, 2018.

[13] B. KoclesGa-Kulpa And T. Szostok, On a functional equation connected to Gauss quadrature rule, Ann. Math. Sil., 22:27-40, 2008.

[14] B. Koclesga-KulPa AND T. Szostok, On some functional equations connected to Hadamard inequalities, Aequationes Math., 75:119-129, 2008.

[15] B. KoclesGa-KulPa AND T. Szostok, On a functional equation connected to Hermite quadrature rule, J. Math. Anal. Appl., 414(2):632-640, 2014.

[16] B. KoclȩGa-Kulpa, T. SZOSTOK, AND SZ. W A̧SOWICZ, On functional equations connected with quadrature rules, Georgian Math. J., 2009. 
[17] B. Koclesga-Kulpa, T. Szostok, And Sz. Wassowicz, On some equations stemming from quadrature rules, Ann. Univ. Paedagog. Crac. Stud. Math., 8:19-30, 2009.

[18] B. KoclȩGA-KulPa, T. SZOSTOK, AND SZ. W A̧SOWICZ, Some functional equations characterizing polynomials, Tatra Mt. Math. Publ., 44:27-40, 2009.

[19] A. LisAK And M. SABliK, Trapezoidal rule revisited, Bull. Inst. Math. Acad. Sin. (N.S.), 6(3):347360, 2011.

[20] L. LosonczI, Equality of Cauchy mean values, Publ. Math. Debrecen, 57:217-230, 2000.

[21] L. LosoncZI, Homogeneous Cauchy mean values, In Z. Daróczy and Zs. Páles, editors, Functional Equations - Results and Advances, volume 3 of Advances in Mathematics, page 209-218. Kluwer Acad. Publ., Dordrecht, 2002.

[22] L. LosonCZI, Inequalities for Cauchy mean values, Math. Inequal. Appl., 5(3):349-359, 2002. Inequalities, 2001 (Timişoara).

[23] L. Losonczi, Equality of two variable Cauchy mean values, Aequationes Math., 65(1-2):61-81, 2003.

[24] A. LundBerg, A rational Sûto equation, Aequationes Math., 57(2-3):254-277, 1999.

[25] A. Lundberg, Sequential derivatives and their application to a Sûto equation, Aequationes Math., 62(1-2):48-59, 2001.

[26] J. MATKOWS KI, Solution of a regularity problem in equality of Cauchy means, Publ. Math. Debrecen, 64(3-4):391-400, 2004.

[27] J. MatKows KI, Mean-value type equalities with interchanged function and derivative, Fasc. Math., (47):19-27, 2011.

[28] I. Pawlikows Ka, A characterization of polynomials through Flett's MVT, Publ. Math. Debrecen, 60:1-14, 2002.

[29] T. Riedel And M. Sablik, Characterizing polynomial functions by a mean value property, Publ. Math. Debrecen, 52(3-4):597-609, 1998.

[30] M. SABLIK, A remark on a mean value property, C. R. Math. Rep. Acad. Sci. Canada, 14(5):207-212, 1992.

[31] M. SABLIK, Taylor's theorem and functional equations, Aequationes Math., 60(3):258-267, 2000.

[32] P. K. Sahoo And T. Riedel, Mean value theorems and functional equations, World Scientific Publishing Co. Inc., River Edge, NJ, 1998.

[33] M. SCHWARZENBERGER, A functional equation related to symmetry of operators, Aequationes Math., 91(4):779-783, 2017.

[34] T. Szostok, The generalized sine function and geometrical properties of normed spaces, Opuscula Math., 35(1):117-126, 2015.

[35] L. SzÉKelYhidi, Convolution Type Functional Equations on Topological Abelian Groups, World Scientific Publishing Co. Inc., Teaneck, NJ, 1991.

[36] P. Volkmann, Une équation fonctionnelle pour les différences divisées, Mathematica (Cluj), 26(49)(2):175-181, 1984.

[37] R. EUKASIK, A note on functionals equations connected with the Cauchy mean value theorem, Aequationes Math., 2018. 